A. GLOWACZ*\#, W. GLOWACZ*, Z. GLOWACZ**, J. KOZIK**, M. GUTTEN***,

D. KORENCIAK***, Z. F. KHAN****, M. IRFAN*****, E. CARLETTI******

\title{
FAULT DIAGNOSIS OF THREE PHASE INDUCTION MOTOR USING CURRENT SIGNAL, MSAF-RATIO15 AND SELECTED CLASSIFIERS
}

\begin{abstract}
A degradation of metallurgical equipment is normal process depended on time. Some factors such as: operation process, friction, high temperature can accelerate the degradation process of metallurgical equipment. In this paper the authors analyzed three phase induction motors. These motors are common used in the metallurgy industry, for example in conveyor belt. The diagnostics of such motors is essential. An early detection of faults prevents financial loss and downtimes. The authors proposed a technique of fault diagnosis based on recognition of currents. The authors analyzed 4 states of three phase induction motor: healthy three phase induction motor, three phase induction motor with 1 faulty rotor bar, three phase induction motor with 2 faulty rotor bars, three phase induction motor with faulty ring of squirrel-cage. An analysis was carried out for original method of feature extraction called MSAF-RATIO15 (Method of Selection of Amplitudes of Frequencies - Ratio 15\% of maximum of amplitude). A classification of feature vectors was performed by Bayes classifier, Linear Discriminant Analysis (LDA) and Nearest Neighbour classifier. The proposed technique of fault diagnosis can be used for protection of three phase induction motors and other rotating electrical machines. In the near future the authors will analyze other motors and faults. There is also idea to use thermal, acoustic, electrical, vibration signal together.
\end{abstract}

Keywords: Fault, current, electrical signal, induction motor, diagnostics, classification

\section{Introduction}

A degradation of metallurgical equipment is normal process depended on time. Some factors such as: operation process, friction, high temperature can accelerate the degradation process of metallurgical equipment. Three phase induction motors are common used in the metallurgy industry, for example in conveyor belt. The diagnostics of such motors is essential. The early detection of faults prevents financial loss and downtimes. In the literature researchers developed methods of fault detection based on acoustic [1-13], thermal [14-20] and vibration signals [21-29]. An acoustic signal is difficult to process because microphone records many sounds from environment. Measurements of temperature are possible when motor is hot. Electrical signals are very good for a recognition for example MCSA(Motor Current Signature Analysis). These kinds of signals do not have many disturbances. The recognition of electrical signals of motors was also described in the literature [30-40]. However more analyses are needed in this topic, to develop more effi- cient methods of fault diagnosis . There are also possibility to diagnose materials such as steel [41] or properties of materials [42]. In this paper the authors analyzed 4 three phase induction motors (Fig. 1).

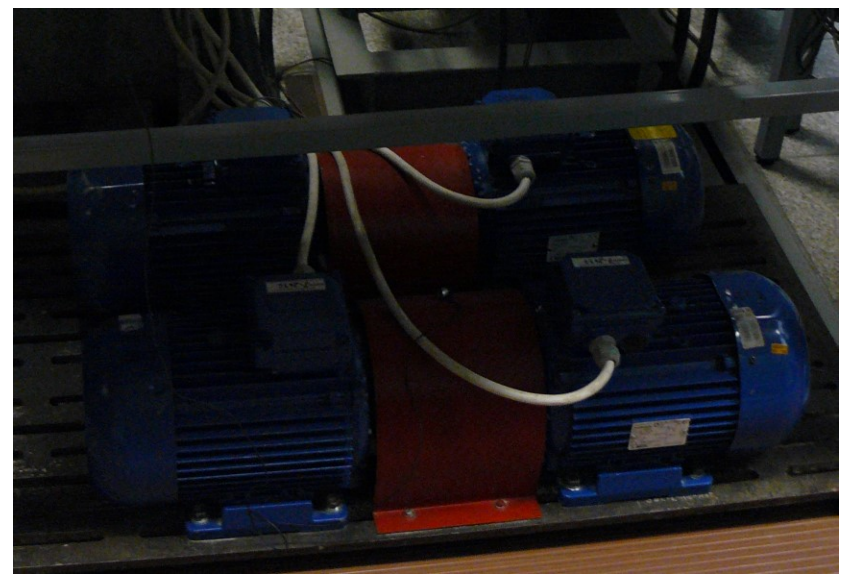

Fig. 1. Four analyzed three phase induction motors

\footnotetext{
AGH UNIVERSITY OF SCIENCE AND TECHNOLOGY, FACULTY OF ELECTRICAL ENGINEERING, AUTOMATICS, COMPUTER SCIENCE AND BIOMEDICAL ENGINEERING, DEPARTMENT OF AUTOMATICS AND BIOMEDICAL ENGINEERING, AL. A. MICKIEWICZA 30, 30-059 KRAKÓW, POLAND

** AGH UNIVERSITY OF SCIENCE AND TECHNOLOGY, FACULTY OF ELECTRICAL ENGINEERING, AUTOMATICS, COMPUTER SCIENCE AND BIOMEDICAL ENGINEERING, DEPARTMENT OF POWER ELECTRONICS AND ENERGY CONTROL SYSTEMS, AL. A. MICKIEWICZA 30, 30-059 KRAKÓW, POLAND

*** UNIVERSITY OF ZILINA, FACULTY OF ELECTRICAL ENGINEERING, 1 UNIVERZITNA STR., 01026 ZILINA, SLOVAKIA

**** SHAQRA UNIVERSITY, COLLEGE OF COMPUTING AND INFORMATION TECHNOLOGY, DEPARTMENT OF COMPUTER SCIENCE, KINGDOM OF SAUDI ARABIA

***** NAJRAN UNIVERSITY, ELECTRICAL ENGINEERING DEPARTMENT, KINGDOM OF SAUDI ARABIA

****** NATIONAL RESEARCH COUNCIL OF ITALY, CNR IMAMOTER, INSTITUTE FOR AGRICULTURAL AND EARTHMOVING MACHINERY, ITALY

\#_Corresponding author: adglow@agh.edu.pl
} 
The authors proposed a technique of fault diagnosis based on recognition of currents.

\section{Technique of fault diagnosis based on recognition of current signal}

The proposed technique of fault diagnosis was based on recognition of current signal. It included a pattern creation process and identification process (Fig. 2).

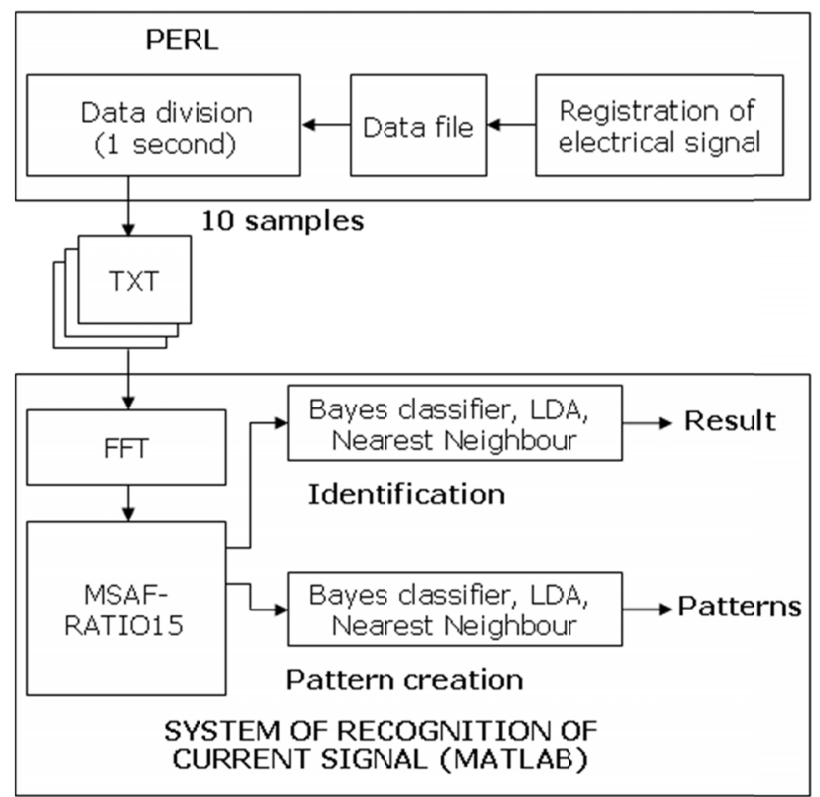

Fig. 2. Technique of fault diagnosis based on recognition of current signal with the use of MSAF-RATIO15 and Bayes classifier, LDA, Nearest Neighbour classifier

Both processes were similar. At the beginning of both processes an electrical (current) signal was recorded. This was done by data acquisition card and a computer. Next obtained signals were divided, converted through windowing (windows size 20000) and the FFT method. Next feature extraction with the use of MSAF-RATIO15 was performed for pattern creation process. The last step of pattern creation process was formulation of patterns - feature vectors. Performing of MSAF-RATIO15 was not necessary for identification process, because all frequencies were calculated in pattern creation process. A test sample was processed and new feature vector was obtained. This vector was compared with patterns with the use of Bayes classifier, Linear Discriminant Analysis (LDA) and Nearest Neighbour classifier.

\subsection{Method of selection of amplitudes of frequencies MSAF-RATIO15}

MSAF-RATIO15 (Method of Selection of Amplitudes of Frequencies - Ratio 15\% of maximum of amplitude) was an original feature extraction method. Figure 3 showed block diagram of MSAF-RATIO15.
1. Calculate the frequency spectrum of current signal for each state of three phase induction motor

\begin{tabular}{|c|}
\hline $\begin{array}{c}\text { 2. Calculate differences between frequencies } \\
\text { spectra of states of three phase induction motor }\end{array}$ \\
\hline 3. Calculate a ratio $R$ for each amplitude of frequency \\
\hline $\begin{array}{c}\text { 4. Select amplitudes of frequencies } \\
\text { for ratio } R \text { greater than } 15 \%\end{array}$ \\
\hline
\end{tabular}

Fig. 3. Block diagram of MSAF-RATIO30-EXPANDED

Specific steps of MSAF-RATIO15 were following:

1) Calculate the frequency spectrum of current signal for each state of three phase induction motor. Frequency spectrum of current signal of healthy three phase induction motor was a vector htpim $=\left[\right.$ htpim $_{1}, h$ tpim $\left._{2}, \ldots, h_{\text {tpim }}{ }_{16384}\right]$. Frequency spectrum of current signal of three phase induction motor

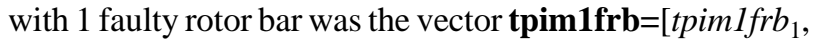
tpim1 1 r $b_{2}, \ldots$, tpim 1 frb $\left._{16384}\right]$. Frequency spectrum of current signal of three phase induction motor with 2 faulty rotor bars was the vector tpim2frb $=\left[\operatorname{tpim} 2 f r b_{1}, \operatorname{tpim} 2 f r b_{2}, \ldots\right.$, tpim2frb $\left.{ }_{16384}\right]$. Frequency spectrum of current signal of three phase induction motor with faulty ring of squirrel-cage was the vector tpimfrsc $=\left[\right.$ tpimfrsc $_{1}$, tpimfrsc $_{2}, \ldots$, tpimfrsc 16384].

2) Calculate differences between frequencies spectra of states of three phase induction motor: |htpim - tpim1frb|, |htpim - tpim2frb|, |htpim - tpimfrsc|, |tpim1frb - tpim2frb|, |tpim1frb - tpimfrsc|, |tpim2frb - tpimfrsc|.

3) Calculate ratio $R$ for each spectrum of frequency. The ratio was expressed by formula (1):

$$
R=(100 \%) A_{i} / A_{\max },
$$

where $A_{i}, A_{\max }$ were based on differences between frequency spectra of training samples, $A_{i}$ - amplitude of frequency with index $i, A_{\max }-$ maximum amplitude in the spectrum of frequency, $R=15 \%$ for MSAF-RATIO15.

4) Select amplitudes of frequencies for ratio $R$ greater than (15\%) $A_{\text {max }}$. Next select common amplitudes of frequencies for all analyzed differences.

5) Form a feature vector.

Differences of frequencies spectra of current signals of three phase induction motor |htpim - tpim1frb|, |htpim - tpim2frb|, |htpim - tpimfrsc|, |tpim1frb - tpim2frb|, |tpim1frb - tpimfrsc|, |tpim2frb - tpimfrsc| were showed in (Figs. 4-9) (rotor speed $1400 \mathrm{rpm})$.

Selected amplitudes of frequencies formed feature vectors. These vectors contained frequencies 26, 51, $76 \mathrm{~Hz}$. Next obtained vectors were used for classification. 


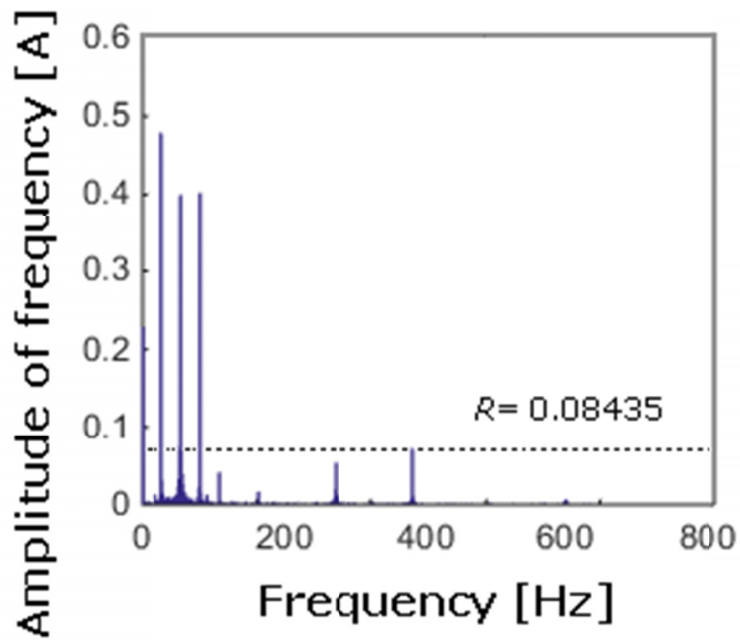

Fig. 4. Difference between spectra of frequencies of current signal of healthy three phase induction motor and three phase induction motor with 1 faulty rotor bar (|htpim - tpim1frb|)

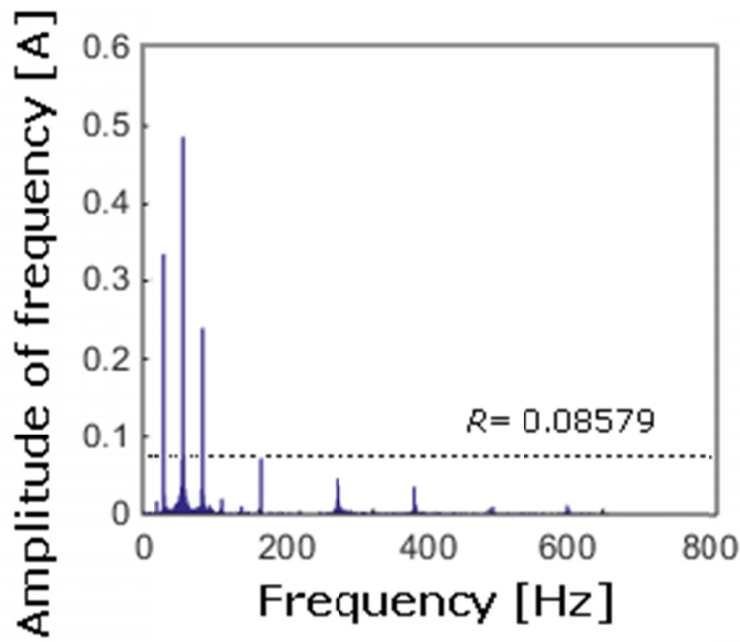

Fig. 5. Difference between spectra of frequencies of current signal of healthy three phase induction motor and three phase induction motor with 2 faulty rotor bars (|htpim - tpim2frb|)

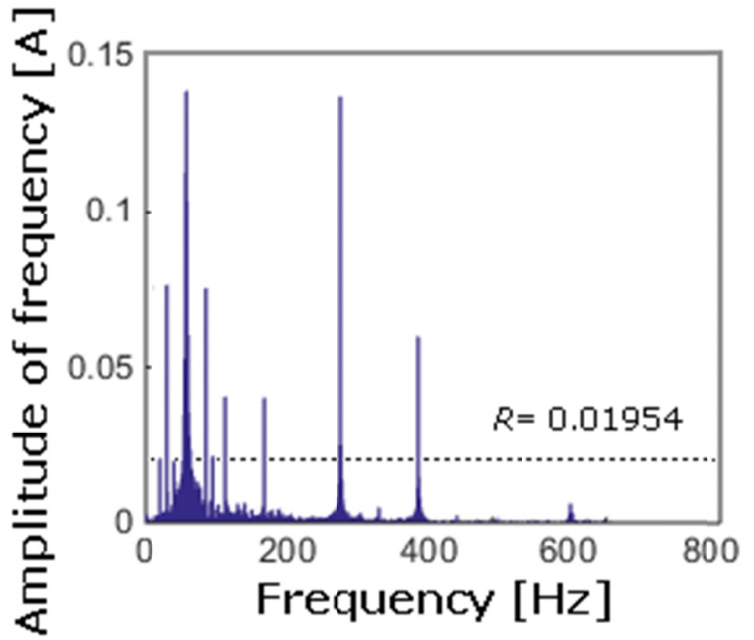

Fig. 6. Difference between spectra of frequencies of current signal of healthy three phase induction motor and three phase induction motor with faulty ring of squirrel-cage (|htpim - tpimfrsc|)

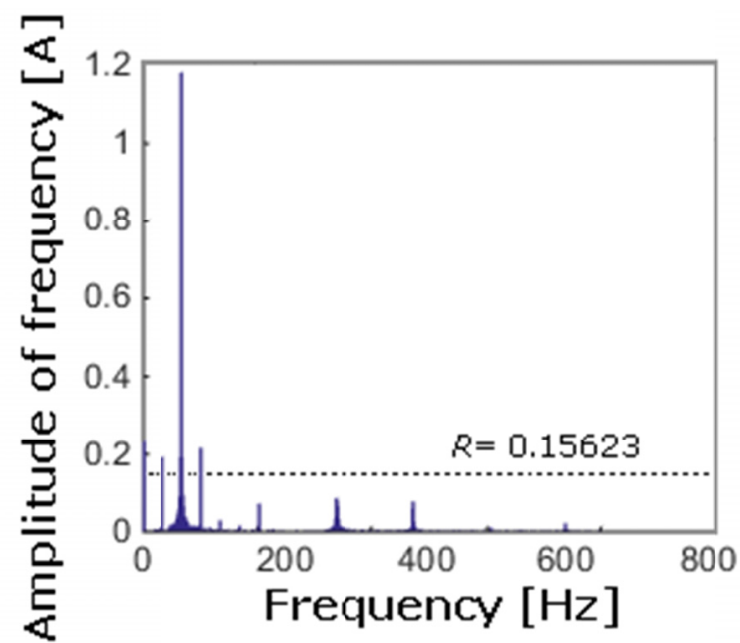

Fig. 7. Difference between spectra of frequencies of current signal of three phase induction motor with 2 faulty rotor bars and three phase induction motor with 1 faulty rotor bar (|tpim2frb - tpim1frb|)

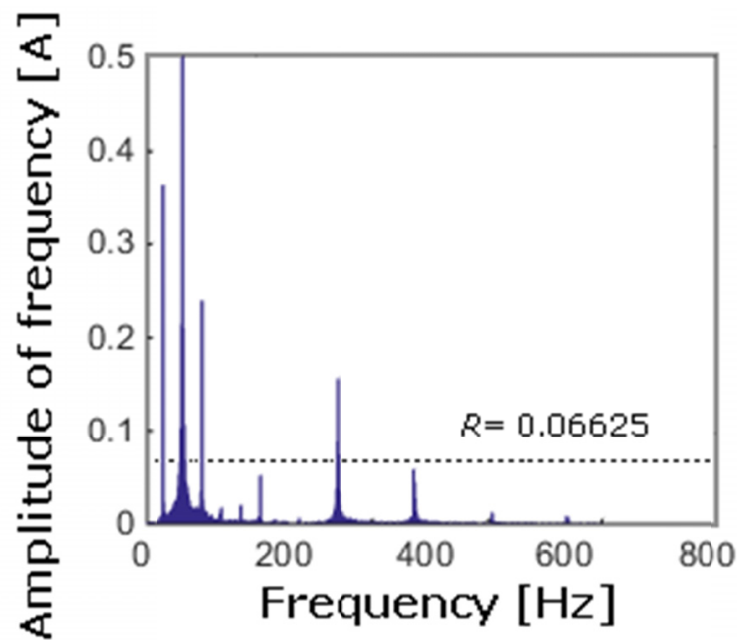

Fig. 8. Difference between spectra of frequencies of current signal of three phase induction motor with 2 faulty rotor bars and three phase induction motor with faulty ring of squirrel-cage (|tpim2frb - tpimfrsc|)

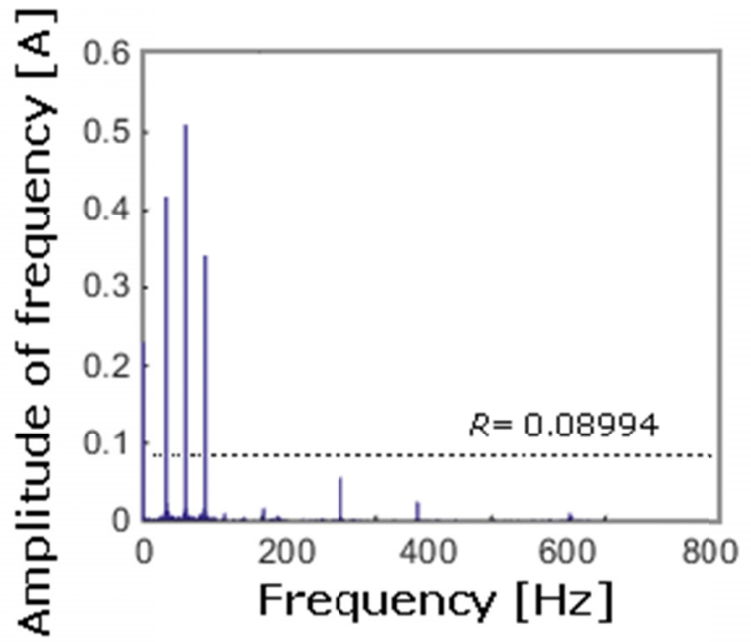

Fig. 9. Difference between spectra of frequencies of current signal of three phase induction motor with 1 faulty rotor bar and three phase induction motor with faulty ring of squirrel-cage (|tpim1frb - tpimfrsc|) 


\subsection{Bayes classifier}

Classification methods were discussed in many articles by many researchers [43-52]. Neural networks were often used for classification problems [53-58]. Statistical data analysis was also described [59]. One of classification methods was Naive Bayes classifier. It was well described in the literature $[48,60]$. This classifier used a posterior probability, which was expressed by (2):

$$
p\left(v_{j} \mid z\right)=\frac{p\left(z \mid v_{j}\right) p\left(v_{j}\right)}{p(z)}
$$

where $p\left(v_{j}\right)$ - probability of occurrence of class $v_{j}, p(z)$ - probability of instance $z, p\left(z \mid v_{j}\right)$ - probability of generating instance $z$ given class $v_{j}, p\left(v_{j} \mid z\right)$ - probability of instance $z$ being in class $v_{j}$.

Classifier calculated the posterior probability for all training feature vectors (patterns) and marked patterns with respect to their category. Next it classified test feature vectors (test samples) according to the higher probability $p\left(v_{j} \mid z\right)$.

\subsection{Linear Discriminant Analysis}

Linear Discriminant Analysis (LDA) was a classification method. It was well described in the literature [61,62]. LDA maximized the component axes for class-separation and created the best hyperplane between training points (training feature vectors). After performance of pattern creation process new test samples were classified. The result of classification was depended on distance between new feature vector and the calculated hyperplane. More information about LDA was available in the literature [61,62].

\subsection{Nearest Neighbour classifier}

The Nearest Neighbour classifier was common used classification method $[48,63,64]$. It was used in many applications such as: robotics, pattern recognition, databases, coding theory, plagiarism detection, spell checking. The application of such classifier for fault detection of three phase induction motor was interesting. The Nearest Neighbour classifier used training and test samples. After performance of pattern creation process new test samples were classified by distance function. The authors decided to use Manhattan distance (3):

$$
M(\text { htpim,tpim1frb })=\sum_{i=1}^{3} \mid\left(\text { tpim }_{i}-\operatorname{tpim} 1 \text { fr } b_{i}\right) \mid
$$

where feature vectors htpim=[htpim ${ }_{26}, h_{t p i m_{51}}, h$ tpim $\left._{76}\right]$ and tpim1frb $=\left[t_{p i m} 1 f_{r} b_{26}, t p i m 1 f r b_{51}, t p i m 1 f r b_{76}\right]$. The calculations were performed for 4 feature vectors: htpim, tpim1frb, tpim2frb, tpimfrsc.

There was a possibility of use other distance functions such as: Euclidean, Minkowski, Chebyshev, cosine, Jacquard.
The results of mentioned distance functions were very similar. More information about the Nearest Neighbour classifier was available in the literature $[48,63,64]$.

\section{Analysis of proposed technique}

Measurements of current signals were performed by data acquisition card and computer. Each of four three phase induction motor had power $550 \mathrm{~W}$ and rotor speed $r_{s}=1400 \mathrm{rpm}$.

\section{Two faulty rotor bars}

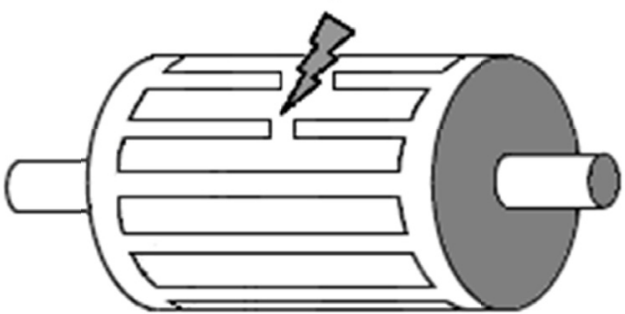

Fig. 10. Squirrel-cage of three-phase induction motor with two faulty rotor bars

The authors analyzed 4 states of three phase induction motor: healthy three phase induction motor, three phase induction motor with 1 faulty rotor bar, three phase induction motor with 2 faulty rotor bars (Fig. 10), three phase induction motor with faulty ring of squirrel-cage.

Feature vectors contained amplitudes of frequencies 26, 51, $76 \mathrm{~Hz}$ (see section 2.1). The training set had 12 one-second samples (vectors). The test set had 40 one-second samples. Efficiency of current signal recognition was defined as (4):

$$
E_{C}=\frac{N_{i p}}{N_{a}} \cdot 100 \%
$$

where: $E_{C}$ - efficiency of current signal recognition, $N_{i p}$ - number of test samples identified properly, $N_{a}$ - number of all test samples.

The authors analyzed 3 classifiers: Bayes classifier, LDA and Nearest Neighbour classifier. The results of all classifiers were the same. Efficiency of current signal recognition was equaled $100 \%$ for 4 states of three phase induction motor (Tab. 1).

TABLE 1

Results of current signal recognition of three phase induction motor with the application of MSAF-RATIO15

\begin{tabular}{|c|c|}
\hline Type of current signal & $\begin{array}{c}\text { Efficiency of current signal } \\
\text { recognition [\%] }\end{array}$ \\
\hline Healthy three phase induction motor & 100 \\
\hline $\begin{array}{c}\text { three phase induction motor with } 1 \\
\text { faulty rotor bar }\end{array}$ & 100 \\
\hline $\begin{array}{c}\text { three phase induction motor with } 2 \\
\text { faulty rotor bars }\end{array}$ & 100 \\
\hline $\begin{array}{c}\text { three phase induction motor with } \\
\text { faulty ring of squirrel-cage }\end{array}$ & 100 \\
\hline
\end{tabular}




\section{Conclusions}

The technique of current signal recognition was presented for three phase induction motor. This technique used the original method of feature extraction MSAF10. The authors analyzed 3 classifiers: Bayes classifier, LDA and the Nearest Neighbour classifier. The results of all classifiers were very good (100\%). The proposed technique of fault diagnosis can be used for protection of three phase induction motors and other rotating electrical machines. It is essential for metallurgy industry. In the near future the authors will analyze other motors and faults. There is also idea to use thermal, acoustic, electrical, vibration signals together.

\section{Acknowledgments}

This work has been partly supported by AGH University of Science and Technology, grant no. 11.11.120.612, grant no. 11.11.120.815, grant no. 11.11.120.354. This work has been partly supported by the Grant Agency VEGA from the Ministry of Education of Slovak Republic under contract 1/0602/17.

\section{REFERENCES}

[1] A. Deptula, D. Kunderman, P. Osinski, U. Radziwanowska, R. Wlostowski, Acoustic diagnostics applications in the study of technical condition of combustion engine, Archives of Acoustics 41, 2, 345-350 (2016).

[2] A. Deptula, P. Osinski, U. Radziwanowska, Decision support system for identifying technical condition of combustion engine, Archives of Acoustics 41, 3, 449-460 (2016).

[3] J. Jozwik, Identification and monitoring of noise sources of CNC machine tools by acoustic holography methods, Advances in Science and Technology-Research Journal 10, 30, 127-137 (2016).

[4] F. Hemmati, W. Orfali, M.S. Gadala, Roller bearing acoustic signature extraction by wavelet packet transform, applications in fault detection and size estimation, Applied Acoustics 104, 101118 (2016)

[5] B. Van Hecke, J. Yoon, D. He, Low speed bearing fault diagnosis using acoustic emission sensors, Applied Acoustics 105, 35-44 (2016).

[6] P.A. Delgado-Arredondo, D. Morinigo-Sotelo, R.A. Osornio-Rios, J.G. Avina-Cervantes, H. Rostro-Gonzalez, R.D. Romero-Troncoso, Methodology for fault detection in induction motors via sound and vibration signals, Mechanical Systems and Signal Processing 83, 568-589 (2017).

[7] A. Glowacz, Z. Glowacz, Diagnosis of stator faults of the single-phase induction motor using acoustic signals, Applied Acoustics 117, Part A, 20-27 (2017).

[8] A. Glowacz, Fault diagnosis of DC motor using acoustic signals and MSAF-RATIO30-EXPANDED, Archives of Electrical Engineering 65, 4, 733-744 (2016).
[9] A. Glowacz, DC Motor Fault Analysis with the Use of Acoustic Signals, Coiflet Wavelet Transform, and K-Nearest Neighbor Classifier, Archives of Acoustics 40, 3, 321-327 (2015).

[10] R. Lara, R. Jimenez-Romero, F. Perez-Hidalgo, M.D. Redel-Macias, Influence of constructive parameters and power signals on sound quality and airborne noise radiated by inverter-fed induction motors, Measurement 73, 503-514 (2015).

[11] S.B. Zhang, S.L. Lu, Q.B. He, F.R. Kong, Time-varying singular value decomposition for periodic transient identification in bearing fault diagnosis, Journal of Sound and Vibration 379, 213-231 (2016).

[12] A. Glowacz, W. Glowacz, Z. Glowacz, J. Kozik, Early fault diagnosis of bearing and stator faults of the single-phase induction motor using acoustic signals, Measurement 113, 1-9 (2018).

[13] A. Glowacz, Diagnostics of Rotor Damages of Three-Phase Induction Motors Using Acoustic Signals and SMOFS-20-EXPANDED, Archives of Acoustics 41, 3, 507-515 (2016).

[14] G. Singh, T.C.A. Kumar, V.N.A. Naikan, Induction motor inter turn fault detection using infrared thermographic analysis, Infrared Physics \& Technology 77, 277-282 (2016).

[15] L.X. Duan, M.C. Yao, J.J. Wang, T.B. Bai, L.B. Zhang, Segmented infrared image analysis for rotating machinery fault diagnosis, Infrared Physics \& Technology 77, 267-276 (2016).

[16] P. Gas, Optimization of multi-slot coaxial antennas for microwave thermotherapy based on the S11-parameter analysis, Biocybernetics and Biomedical Engineering 37, 1, 78-93 (2017).

[17] H. Liu, Z X. Wang, J. Zhong, Z W. Xie, Early detection of spontaneous combustion disaster of sulphide ore stockpiles, Tehnicki Vjesnik-Technical Gazette 22, 6, 1579-1587 (2015).

[18] R. Koprowski, Some selected quantitative methods of thermal image analysis in Matlab, Journal of Biophotonics 9, 5, 510-520 (2016).

[19] A. Glowacz, Z. Glowacz, Diagnosis of the three-phase induction motor using thermal imaging, Infrared Physics \& Technology 81,7-16 (2017).

[20] R. Barlik, M. Nowak, P. Grzejszczak, M. Zdanowski, Estimation of power losses in a high-frequency planar transformer using a thermal camera, Archives of Electrical Engineering 65, 3, 613627 (2016).

[21] Z.X. Li, Y. Jiang, C. Hu, Z. Peng, Recent progress on decoupling diagnosis of hybrid failures in gear transmission systems using vibration sensor signal: A review, Measurement 90, 4-19 (2016).

[22] Y. Jiang, Z.X. Li, C. Zhang, C. Hu, Z. Peng, On the bi-dimensional variational decomposition applied to nonstationary vibration signals for rolling bearing crack detection in coal cutters, Measurement Science and Technology 27, 6, (2016).

[23] L. Jedlinski, J. Caban, L. Krzywonos, S. Wierzbicki, F. Brumercik, Application of vibration signal in the diagnosis of IC engine valve clearance, Journal of Vibroengineering 17, 1, 175-187 (2015).

[24] G.M. Krolczyk, J.B. Krolczyk, S. Legutko, A. Hunjet, Effect of the disc processing technology on the vibration level of the chipper during operations, Tehnicki Vjesnik-Technical Gazette 21, 2, 447-450 (2014).

[25] W. Sawczuk, G.M. Szymanski, Diagnostics of the railway friction disc brake based on the analysis of the vibration signals in terms 
of resonant frequency, Archive of Applied Mechanics 87, 5, 801815 (2017).

[26] D. Camarena-Martinez, M. Valtierra-Rodriguez, J.P. Amezquita-Sanchez, D. Granados-Lieberman, R.J. Romero-Troncoso, A. Garcia-Perez, Shannon entropy and k-means method for automatic diagnosis of broken rotor bars in induction motors using vibration signals, Shock and Vibration, Article Number: 4860309 (2016).

[27] A. Prudhom, J. Antonino-Daviu, H. Razik, V. Climente-Alarcon, Time-frequency vibration analysis for the detection of motor damages caused by bearing currents, Mechanical Systems and Signal Processing 84, 747-762 (2017).

[28] W. Sawczuk, The Application of Vibration Accelerations in the Assessment of Average Friction Coefficient of a Railway Brake Disc, Measurement Science Review 17, 3, 125-134 (2017).

[29] S. Adamczak, K. Stepien, M. Wrzochal, Comparative study of measurement systems used to evaluate vibrations of rolling bearings, Procedia Engineering 192, 971-975 (2017).

[30] Z. Glowacz, A. Glowacz, Simulation language for analysis of discrete-continuous electrical systems (SESL2), Proceedings of the 26th IASTED International Conference on Modelling, Identification, and Control, Innsbruck, Austria, 94-99 (2007).

[31] A. Glowacz, W. Glowacz, Z. Glowacz, Recognition of armature current of DC generator depending on rotor speed using FFT, MSAF-1 and LDA, Eksploatacja i Niezawodnosc - Maintenance and Reliability 17, 1, 64-69 (2015).

[32] M. Michalak, M. Sikora, J. Sobczyk, Analysis of the longwall conveyor chain based on a harmonic analysis, Eksploatacja i Niezawodnosc - Maintenance and Reliability 15, 4, 332-336 (2013).

[33] M. Sulowicz, K. Weinreb, R. Mielnik, T. Zywczak, M. Jaraczewski, The method of current measurement in the rotor cage bars of prototype induction motor with the use of Rogowski coils, International Conference on Information and Digital Technologies (IDT), 357-365 (2015).

[34] G.H. Bazan, P.R. Scalassara, W. Endo, A. Goedtel, W.F. Godoy, R.H.C. Palacios, Stator fault analysis of three-phase induction motors using information measures and artificial neural networks, Electric Power Systems Research 143, 347-356 (2017).

[35] R. Yousefi, R. Yusof, R. Arfa, Fault diagnosis of three-phase induction motors based on vibration and electrical current signals, Jurnal Teknologi 78, 9, 129-133 (2016).

[36] T. Ince, S. Kiranyaz, L. Eren, M. Askar, M. Gabbouj, Real-Time Motor Fault Detection by 1-D Convolutional Neural Networks, IEEE Transactions on Industrial Electronics 63, 11, 7067-7075 (2016).

[37] C. Verucchi, J. Bossio, G. Bossio, G. Acosta, Misalignment detection in induction motors with flexible coupling by means of estimated torque analysis and MCSA, Mechanical Systems and Signal Processing 80, 570-581 (2016).

[38] T. Yang, H.B. Pen, Z.X. Wang, C.S. Chang, Feature Knowledge Based Fault Detection of Induction Motors Through the Analysis of Stator Current Data, IEEE Transactions on Instrumentation and Measurement 65, 3, 549-558 (2016).

[39] J.A. Antonino-Daviu, K.N. Gyftakis, R. Garcia-Hernandez, H. Razik, A.J.M. Cardoso, Comparative Influence of Adjacent and Non-adjacent Broken Rotor Bars on the Induction Motor Diagnosis through MCSA and ZSC Methods, IECON 2015 - 41st Annual Conference of the IEEE Industrial Electronics Society, Book Series: IEEE Industrial Electronics Society, 1680-1685 (2015).

[40] T. Ciszewski, L. Gelman, L. Swedrowski, Current-based higher-order spectral covariance as a bearing diagnostic feature for induction motors, Insight, 58, 8, 431-434 (2016).

[41] J.B. Krolczyk, B. Gapinski, G.M. Krolczyk, I. Samardzic, R.W. Maruda, K. Soucek, S. Legutko, P. Nieslony, Y. Javadi, L. Stas, Topographic inspection as a method of weld joint diagnostic, Tehnicki Vjesnik-Technical Gazette 23, 1, 301-306 (2016).

[42] M. Wiewiora, M. Wedrychowicz, L. Wzorek, Mechanical properties of solid state recycled 6060 aluminum alloy chips, METAL 2015: 24th International Conference on Metallurgy and Materials, 1674-1679 (2015).

[43] Y.G. Zhang, J.Y. Yang, K.C. Wang, Z.P. Wang, Wind Power Prediction Considering Nonlinear Atmospheric Disturbances, Energies 8, 1, 475-489 (2015).

[44] Y.G. Zhang, P.H. Wang, T. Ni, PL. Cheng, S. Lei, Wind Power Prediction Based on LS-SVM Model with Error Correction, Advances in Electrical and Computer Engineering 17, 1, 3-8 (2017).

[45] D. Valis, L. Zak, O. Pokora, P. Lansky, Perspective analysis outcomes of selected tribodiagnostic data used as input for condition based maintenance, Reliability Engineering \& System Safety 145, 231-242 (2016).

[46] Z. Vintr, D. Valis, A Tool for Decision Making in k-out-of-n System Maintenance, Applied Mechanics and Materials 110-116, 5257-5264 (2012).

[47] T. Hachaj, Pattern Classification Methods for Analysis and Visualization of Brain Perfusion CT Maps, Computational Intelligence Paradigms in Advanced Pattern Classification, Book Series: Studies in Computational Intelligence 386, 145-170 (2012).

[48] R.H.C. Palacios, I.N. da Silva, A. Goedtel, W.F. Godoy, A comprehensive evaluation of intelligent classifiers for fault identification in three-phase induction motors, Electric Power Systems Research 127, 249-258 (2015).

[49] R. Koprowski, M. Lanza, C. Irregolare, Corneal power evaluation after myopic corneal refractive surgery using artificial neural networks. BioMedical Engineering OnLine 15, Article Number: 121 (2016).

[50] D. Wilk-Kolodziejczyk, K. Regulski, G. Gumienny, Comparative analysis of the properties of the nodular cast iron with carbides and the austempered ductile iron with use of the machine learning and the support vector machine, International Journal of Advanced Manufacturing Technology 87, 1-4, 1077-1093 (2016).

[51] G. Rojek, K. Regulski, D. Wilk-Kolodziejczyk, S. Kluska-Nawarecka, K. Jaskowiec, A. Smolarek-Grzyb, Methods of Computational Intelligence in the Context of Quality Assurance in Foundry Products, Archives of Foundry Engineering 16, 2, 11-16 (2016).

[52] D. Valis, L. Zak, Contribution to prediction of soft and hard failure occurrence in combustion engine using oil tribo data, Engineering Failure Analysis 82, 583-598 (2017). 
[53] D. Jamroz, T. Niedoba, Application of multidimensional data visualization by means of self-organizing Kohonen maps to evaluate classification possibilities of various coal types, Archives of Mining Sciences 60, 1, 39-50 (2015).

[54] Z.B. Hu, J. Su, V. Jotsov, O. Kochan, M. Mykyichuk, R. Kochan, T. Sasiuk, Data Science Applications to Improve Accuracy of Thermocouples. 2016 IEEE 8th International Conference on Intelligent Systems (IS), 180-188 (2016).

[55] J. Roj, A. Cichy, Method of Measurement of Capacitance and Dielectric Loss Factor Using Artificial Neural Networks, Measurement Science Review 15, 3, 127-131 (2015).

[56] R. Tadeusiewicz, Neural networks in mining sciences-general overview and some representative examples, Archives of Mining Sciences 60, 4, 971-984 (2015).

[57] M. Walenczykowska, A. Kawalec, Type of modulation identification using Wavelet Transform and Neural Network, Bulletin of the Polish Academy of Sciences-Technical Sciences 64, 1, 257-261 (2016).

[58] M. Jablonski, P. Tylek, J. Walczyk, R. Tadeusiewicz, A. Pilat, Colour-Based Binary Discrimination of Scarified Quercus robur Acorns under Varying Illumination, Sensors 16, 8, (2016).

[59] K. Proniewska, K. Malinowski, E. Pociask, B. Proniewski, Classification of Sleep Disordered Breathing in the Evaluation of Acoustic Sound in Correlation with the ECG Signal, 2014 Computing in Cardiology Conference (CINC), Book Series: Computing in Cardiology Series 41, 153-156 (2014).

[60] J. Karandikar, T. McLeay, S. Turner, T. Schmitz, Tool wear monitoring using naive Bayes classifiers, International Journal of Advanced Manufacturing Technology 77, 9-12, 1613-1626 (2015).

[61] Y.A. Ghassabeh, F. Rudzicz, H.A. Moghaddam, Fast incremental LDA feature extraction, Pattern Recognition 48, 6, 1999-2012 (2015).

[62] R.Z. Haddad, E.G. Strangas, On the Accuracy of Fault Detection and Separation in Permanent Magnet Synchronous Machines Using MCSA/MVSA and LDA, IEEE Transactions on Energy Conversion 31, 3, 924-934 (2016).

[63] A. Glowacz, A. Glowacz, Z. Glowacz, Diagnostics of Direct Current generator based on analysis of monochrome infrared images with the application of cross-sectional image and nearest neighbor classifier with Euclidean distance, Przeglad Elektrotechniczny 88, 6, 154-157 (2012).

[64] I. Bandyopadhyay, P. Purkait, C. Koley, A combined image processing and Nearest Neighbor Algorithm tool for classification of incipient faults in induction motor drives, Computers \& Electrical Engineering 54, 296-312 (2016). 